Article

\title{
Effect of Calcium Chloride as a Coagulant on the Properties of ESBR/Silica Wet Masterbatch Compound
}

\author{
Woong Kim ${ }^{\mathbb{D}}$, Byungkyu Ahn, Hyunsung Mun, Eunho Yu, Kiwon Hwang, Donghyuk Kim, \\ Gyeongchan Ryu and Wonho Kim * \\ Department of Polymer Science \& Chemical Engineering, Pusan National University, Busandaehak-ro \\ 63beon-gil, Geumjeong-gu, Busan 46241, Korea; kw65651294@gmail.com (W.K.); bkahn8855@gmail.com (B.A.); \\ ansehdwns10@gmail.com (H.M.); yueh5352@gmail.com (E.Y.); kiwon8348@gmail.com (K.H.); \\ ehdgurzxc@gmail.com (D.K.); 60chan95@gmail.com (G.R.) \\ * Correspondence: whkim@pusan.ac.kr; Tel.: +82-51-510-3190
}

Received: 1 September 2018; Accepted: 4 October 2018; Published: 9 October 2018

check for updates

\begin{abstract}
When designing rubber compounds for high-performance tires, increasing the silica content can improve the wet traction performance but decreases the fuel efficiency. This trade-off relation makes it difficult to improve the two factors simultaneously. One approach is the development of silica wet masterbatch (WMB) technology for producing compounds containing a high silica content with good dispersion. The technology involves a step to mix surface-modified silica and rubber latex. The technique requires a coagulant to break up the micelles of the rubber latex and cause the surface-modified silica and the rubber molecules to co-coagulate due to van der Waals forces. In this study, the effect of coagulant type on the characteristics of silica surface, and the mechanical properties of the emulsion styrene-butadiene rubber (ESBR)/silica WMB compounds was investigated, as well as the abrasion properties and the viscoelastic properties of the vulcanizates.
\end{abstract}

Keywords: polymer composite; silica filled compound; rubber; emulsion styrene-butadiene rubber/silica wet masterbatch; silica dispersion

\section{Introduction}

Rolling resistance and wet traction are the important factors in tire performances related to fuel consumption and safety during the driving of the vehicle. These factors must be considered in the design of rubber compounds used for tire tread [1-4]. In general, it is known that the good wet traction performance of a tire (high $\tan \delta$ value at $0{ }^{\circ} \mathrm{C}$ ) is shown when there is high filler content, functionalized polymer with high filler-rubber affinity, and good filler dispersion [4-6]. The rolling resistance is also known to be lower (good fuel efficiency characteristics) when $\tan \delta$ at $60^{\circ} \mathrm{C}$ of the vulcanizates is lowered by the time-temperature superposition principle. Highly effective methods for low rolling resistance include reducing the filler content, improving filler dispersion, and using functionalized polymer with high filler affinity $[3,6,7]$. In other words, improving both the fuel efficiency and wet traction performance of the tire requires the use of functionalized polymers and high content as well as best dispersion of reinforcing agent in the tread rubber compound [6,8]. However, when functionalized polymer is used, the raw material cost is higher than that of non-functionalized polymer [9], so increasing the content and improving filler dispersion are the priority.

Currently, silica is the dominant filler used in the tire industry. Hydrophilic silanol groups ( $\mathrm{Si}-\mathrm{OH})$ are present on the silica surface, so the interaction with hydrophobic unfunctionalized polymer is low and it is difficult to obtain sufficient filler-rubber interaction (F-R interaction), even when silica-friendly 
functional polymer is used. Therefore, a silane coupling agent must be used to effectively disperse silica in silica filled rubber compounds by silanization reaction $[10,11]$. However, despite the use of a silane coupling agent, the filler-filler interaction (F-F interaction) is still strong due to hydrogen bonding between the residual silanol groups when a high content of silica is added, which remains a disadvantage [12]. F-F interactions are particularly problematic when high silica content in tire tread compounds is used to improve wet traction performance. The result is that the rolling resistance is increased when silica content is increased [6]. Therefore, in order to simultaneously improve both performances in the trade-off relationship, a new material is required, containing a high content of silica with a good dispersion. To prepare this material, silica wet masterbatch (silica WMB) technology has been developed $[13,14]$.

Silica WMB technology refers to a technique of preparing composites of rubber/silica/silane coupling agent by mixing a rubber solution or rubber latex with surface-modified silica, followed by a stripping or coagulation process. The advantages of this technology are the production of silica compounds with a high silica content and good dispersion, improved energy efficiency of the tire manufacturing process, reduced emission of ethanol, and lower hysteresis (lower rolling resistance) [15-17].

Currently, silica WMB technology researchers at petrochemical and tire companies are mainly focused on manufacturing and evaluating the solution styrene-butadiene rubber (SSBR)/silica WMB. These studies showed that SSBR/silica WMB compounds had a $20 \%$ lower rolling resistance and $18 \%$ improved wet traction performance than the DMB compound (dry masterbatch, conventional mixing). However, SSBR/silica WMB technology had a problem, as it generated organic solvent vapor during stripping $[18,19]$. In the university laboratory scale, it is difficult to treat and recover the organic solvent vapor generated during the stripping process. Therefore, emulsion styrene-butadiene rubber (ESBR)/silica WMB and natural rubber (NR)/silica WMB using rubber latex are mainly studied, which use the coagulation technique to obtain WMB compounds [20-22].

In general, micelles dispersed in water by a saponified emulsifier surrounding a rubber molecule, are called a rubber latex. The latex shows basicity ( $\mathrm{pH} 9 \sim 10)$ due to the $\mathrm{OH}$ anion from $\mathrm{KOH}$ used in the saponification of emulsifier. By the addition of coagulant into the latex, coagulation will be started [23-25]. Coagulation mechanism is shown in Figure 1.
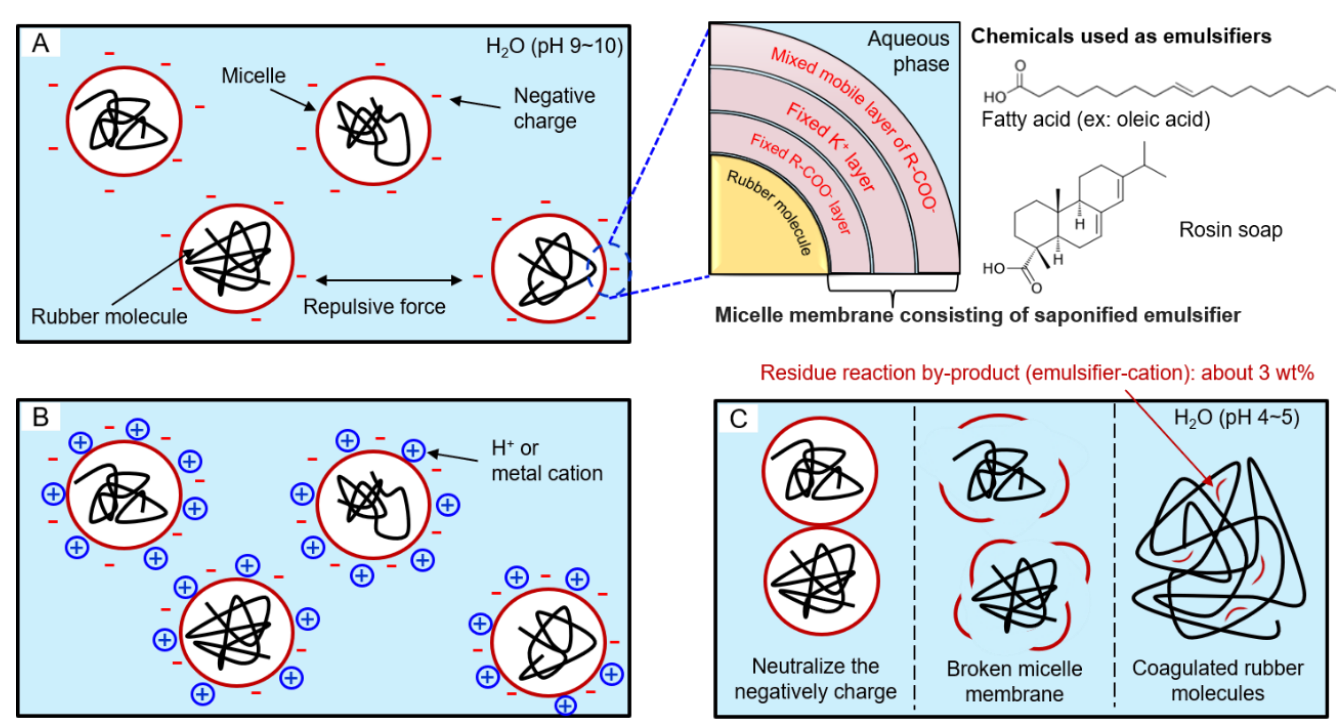

Figure 1. Coagulation mechanism of synthetic rubber such as emulsion styrene-butadiene rubber (ESBR): (A) a state in which a micelle having a negative surface charge is dispersed in water, (B) a state after adding coagulant in latex, and (C) a state of micelle destruction due to collision between neutralized micelles. 
However, the detailed reaction mechanism (reactions between the emulsifier and the coagulant and between the coagulant and silica) that occurs during the preparation of emulsion silica WMB is not yet known. Also, there are insufficient researches on the compounds which applied application of WMB technology. However, we studied about the best blending method of ESBR WMB/butadiene rubber (BR) in our previous study [26]. In this study, we researched the effect of coagulants on the properties of ESBR/silica compounds. In detail, we determined the reaction mechanism of emulsion SBR silica WMB and the suitable manufacturing conditions. The study was carried out using three types of coagulants commonly used in manufacturing of ESBR/silica WMB; aqueous solutions of $1 \mathrm{M}$ sulfuric acid, $25 \mathrm{wt} \%$ sodium chloride, and $2 \mathrm{wt} \%$ calcium chloride. The effect of coagulants on the silica dispersion, mechanical properties, and dynamic viscoelastic properties of ESBR/silica WMB compounds was investigated. We also studied specific improvements of ESBR/silica WMB by comparing the properties with those of existing DMB compound.

\section{Materials and Experimental Methods}

\subsection{Materials}

To determine the optimal type of modified silica for ESBR/silica WMB, the degree of hydrophobation of silica (Newsil 175, Quechen Silicon Chemical CO., Ltd., Wuxi, China, BET surface area: $175 \mathrm{~m}^{2} / \mathrm{g}$ ) treated with $8,10,12,15 \mathrm{wt} \%$ of bis[3-(triethoxysilyl)propyl]tetrasulfide (TESPT, Evonik, Essen, Germany) to silica was compared. Detailed information of TESPT-modified silica was shown in Table 1.

Table 1. BET surface area of TESPT modified silica according to TESPT content.

\begin{tabular}{cccc}
\hline Commercial product name & Commercial source & TESPT $(\mathbf{w t} \mathbf{\% )}$ & BET surface area $\left(\mathbf{m}^{\mathbf{2}} \mathbf{g}\right)$ \\
\hline NK136 & & 8 & 126 \\
NK137 & Miraesi Inc., Gwangju, & 10 & 120 \\
NK153 & Korea & 12 & 116 \\
NK138 & & 15 & 120 \\
\hline
\end{tabular}

After these experiments (Section 2.2), the materials prepared using $12 \mathrm{wt} \%$ were selected for further use in ESBR/silica WMB experiments. The ESBR latex and processing oil used were SBR-1712 (Kumho Petrochemical Co., Daejeon, South Korea, styrene content: 23.5\%, non-oil extended) and treated distillate aromatic extracted (TDAE) oil. For the coagulation process of ESBR/silica WMB, the coagulants used were aqueous solutions of $1 \mathrm{M}$ sulfuric acid (Daejung Chemical \& Metals Co. Siheung, South Korea), 25 wt \% sodium chloride (Samchun Chemical, Seoul, South Korea), and 2 wt \% calcium chloride (Samchun Chemical).

The DMB compound (T-1) was prepared for comparison with the WMB compounds using pure silica, TESPT, and SBR-1723 (Kumho Petrochemical Co., styrene content: $23.5 \mathrm{wt} \%, 37.5 \mathrm{phr}$ TDAE oil extend). Zinc oxide ( $\mathrm{ZnO}$ ) and stearic acid (St/A), which act as activators, and $\mathrm{N}$-(1,3-dimethyl-butyl)$N^{\prime}$-phenyl-p-phenylenediamine (6PPD) as an antioxidant were added during the compounding process of the kneader. In the final masterbatch (FMB) step, sulfur, $n$-cyclohexyl-2-benzothiazole sulfonamide (CBS), and diphenyl guanidine (DPG) were added as crosslinking agents and cure accelerators.

To analyze the effect of the alkali-silica reaction, which is the reaction between the calcium cation and the silanol group on the silica surface, Ca-coated $12 \mathrm{wt} \%$ TESPT-modified silica was manufactured using calcium hydroxide (Daejung Chemical \& Metals Co.) and ethanol (Daejung Chemical \& Metals Co.).

The hydrophobation of modified silica was measured using di-butylamine ( $>99.5 \%$, Sigma Aldrich, St. Louis, MI, USA), petroleum benzine ( $>90 \%$, Samchun Chemical), chloroform $(>99.5 \%$, Samchun Chemical), crystal violet indicator ( $>90 \%$, Sigma Aldrich), perchloric acid ( $>70 \%$, Samchun Chemical), and acetic anhydride ( $>99 \%$, Samchun Chemical). The crosslink density was measured using 
tetrahydrofuran ( $>99.5 \%$, Daejung Chemical \& Metals Co.), $n$-hexane ( $>96 \%$, Daejung Chemical \& Metals Co.), toluene ( $>99.5 \%$, Daejung Chemical \& Metals Co.), and acetone ( $>99.9 \%$, Daejung Chemical \& Metals Co.).

\subsection{Experimental Methods}

\subsubsection{Analysis of Modified Silica and Ca-Coated TESPT-Modified Silica}

Di-n-butylamine (DBA) adsorption analysis can quantitatively demonstrate the hydrophobation of surface-modified silica. The degree of hydrophobation of modified silica can be measured by titrating the amount of unabsorbed DBA to the silica silanol groups.

In detail, after the surface-modified silica was dried at $105^{\circ} \mathrm{C}$ for $2 \mathrm{~h}, 250 \mathrm{mg}$ of the obtained silica was added to $50 \mathrm{~mL}$ of petroleum benzine solution in which $0.002 \mathrm{~N}$ DBA was dissolved and then stored at $20^{\circ} \mathrm{C}$ for $2 \mathrm{~h}$. Then, $25 \mathrm{~mL}$ of the upper layer solution was sampled, mixed with $5 \mathrm{~mL}$ of chloroform and 2-3 drops of crystal violet indicator, and then titrated with acetic anhydride solution containing $0.01 \mathrm{~N}$ perchloric acid. When the color of the solution changed from violet to blue, the volume $(\mathrm{mL})$ of the perchloric acid/acetic anhydride solution added up to this point was determined [27]. We measured the titration solution volume value of each sample 3 times and then obtained an average value $(\mathrm{mL})$.

Substituting the calculated volume of titration solution into Equation (1) gives the number of moles of DBA adsorbed on the silica surface, which can then be substituted into Equation (2) to obtain the hydrophobation of the modified silica.

$$
\text { DBA adsorption }\left(\frac{\mathrm{mmol}}{\mathrm{kg}}\right)=80 *(\beta-\alpha) * f
$$

where $\alpha$ is the titration value $(\mathrm{mL})$ when color change occurs with silica, $\beta$ is the titration value $(\mathrm{mL})$ when color change occurs without silica, and $f$ is the chemical potency of $0.01 \mathrm{~N}$ perchloric acid solution.

$$
\text { Hydrophobation ratio }(\%)=100-\left(\mathrm{DBA} / \mathrm{DBA}^{\prime}\right) \times 100
$$

where DBA $\left(\mathrm{mmol} \cdot \mathrm{kg}^{-1}\right)$ is the DBA adsorption on modified silica and DBA' $\left(\mathrm{mmol} \cdot \mathrm{kg}^{-1}\right)$ is the DBA adsorption on pure silica.

To analyze the effect of the alkali-silica reaction, which is a reaction between the calcium ions produced by ionization from calcium chloride used as a coagulant and the silanol groups of silica, Ca-coated TESPT-modified silica was manufactured using similar conditions to those used for ESBR/silica WMB manufacturing [28]. First, surface-modified silica slurry was prepared by mixing $12 \mathrm{wt} \%$ TESPT-modified silica with distilled water for $15 \mathrm{~min}$. In order to show the same $\mathrm{pH}$ value of calcium ion supply and basic rubber latex, $25 \mathrm{wt} \%$ calcium hydroxide aqueous solution was added to the above surface-modified silica slurry to adjust the $\mathrm{pH}$ value to 9. After that, the Ca-coated $12 \mathrm{wt} \%$ TESPT-modified silica was filtered from the silica slurry using a vacuum filtration apparatus and washed 3 times with ethanol. The prepared Ca-coated TESPT-modified silica was analyzed using X-ray fluorescence (EDX-7000, Shimadzu, Kyoto, Japan) and analyzed for hydrophobation by DBA adsorption.

\subsubsection{Manufacturing of ESBR/Silica WMBs}

The $89.6 \mathrm{phr}$ of $12 \mathrm{wt} \%$ TESPT-modified silica was added to $1 \mathrm{~L}$ distilled water and the mixture was stirred at $60^{\circ} \mathrm{C}$ for $15 \mathrm{~min}$ to prepare a modified silica slurry. The modified silica slurry was mixed with SBR-1712 latex containing $100 \mathrm{phr}$ solid ESBR, heated to $60{ }^{\circ} \mathrm{C}$ and further stirred for $30 \mathrm{~min}$. And added $37.5 \mathrm{phr}$ TDAE oil emulsion into heated mixture, stirring for $30 \mathrm{~min}$. WMBs were prepared using three types of coagulants: $1 \mathrm{M}$ aqueous sulfuric acid solution $200 \mathrm{~mL}$ (WMB T-2), $1 \mathrm{M}$ aqueous sulfuric acid solution $15 \mathrm{~mL}$ combined with a $25 \mathrm{wt} \%$ sodium chloride solution $300 \mathrm{~mL}$ (WMB T-3), 
and $2 \mathrm{wt} \%$ calcium chloride aqueous solution $300 \mathrm{~mL}$ (WMB T-4). Thereafter, ESBR/silica WMBs were washed 4 times using distilled water before drying in a convection oven at $60^{\circ} \mathrm{C}$ for $12 \mathrm{~h}$.

\subsubsection{Characterization of WMBs}

The silica content of ESBR/silica WMB was measured by thermogravimetric analysis (TGA 550, TA Instruments Korea, Seoul, South Korea). The measurement was carried out by increasing the temperature from room temperature to $900{ }^{\circ} \mathrm{C}$ at a rate of $10^{\circ} \mathrm{C} \cdot \mathrm{min}^{-1}$ under a nitrogen atmosphere, and then measuring the silica content by substituting the measured data into Equation (3).

$$
\text { Silica }(\mathrm{phr})=\frac{A}{B} \times 100
$$

where $A$ is the ash percentage (pure silica weight percent) and $B$ is the weight loss percentage between 360 and $900{ }^{\circ} \mathrm{C}$ (SBR weight percent).

In addition, the acidity $(\mathrm{pH})$ of ESBR/silica WMB was indirectly measured in order to investigate additional properties depending on the type of coagulant. For the detailed procedure, $1 \mathrm{~g}$ of dried ESBR/silica WMB sample was immersed in $50 \mathrm{~mL}$ of distilled water. After $2 \mathrm{~h}$ of storage at $50{ }^{\circ} \mathrm{C}$, the $\mathrm{WMB}$ sample was filtered and the $\mathrm{pH}$ of the residual solution was measured 3 times using a $\mathrm{pH}$ meter [29].

\subsubsection{Compounding of WMB Compounds and DMB Compound}

The rubber compound was prepared by applying a fill factor of 0.7 using a closed mixer ( $300 \mathrm{cc}$, Miraesi Inc.). Compounding was carried out in a silica masterbatch (SMB) stage at a starting temperature of $120^{\circ} \mathrm{C}$ for $12 \mathrm{~min}$, dump temperature was $155^{\circ} \mathrm{C}$. The detailed formulations and mixing procedures for T-1 to T- 4 are shown in Tables 2 and 3.

Table 2. Formulation of wet masterbatch (WMB) compounds and dry masterbatch (DMB) compound according to the coagulant type.

\begin{tabular}{ccccc}
\hline \multirow{2}{*}{ Components (phr) } & DMB & \multicolumn{3}{c}{ WMB } \\
\cline { 2 - 5 } & T-1 & T-2 & T-3 & T-4 \\
\hline SBR-1723 & 137.5 & - & - & - \\
WMB T-2 $\left(\mathrm{H}_{2} \mathrm{SO}_{4}\right)$ & - & $219.4^{(\mathrm{a})}$ & - & - \\
WMB T-3 $\left(\mathrm{H}_{2} \mathrm{SO}_{4}+\mathrm{NaCl}\right)$ & - & - & $220.2^{(\mathrm{b})}$ & - \\
WMB T-4 $\left(\mathrm{CaCl}_{2}\right)$ & - & - & - & $223.0^{(\mathrm{c})}$ \\
Pure silica & 80 & - & - & - \\
TESPT & 9.6 & - & - & 3 \\
ZnO & 3 & 3 & 3 & 2 \\
St/A & 2 & 1 & 2 & 1 \\
6PPD & 1 & & 1 & 1.5 \\
Sulfur & & 1.5 & 1.5 & 1.5 \\
CBS & 1.5 & 1.5 & 1.5 & 1.5 \\
DPG & 1.5 & 1.5 & 1.5 &
\end{tabular}

(a): SBR $100 \mathrm{phr}+$ silica $73.1 \mathrm{phr}+$ TESPT $8.8 \mathrm{phr}+$ TDAE oil $37.5 \mathrm{phr}$; (b) SBR $100 \mathrm{phr}+$ silica $73.8 \mathrm{phr}+$ TESPT 8.9 $\mathrm{phr}+$ TDAE oil $37.5 \mathrm{phr}$; (c) SBR $100 \mathrm{phr}+$ silica $76.3 \mathrm{phr}+$ TESPT $9.2 \mathrm{phr}+$ TDAE oil $37.5 \mathrm{phr}$. 
Table 3. Mixing procedures for the DMB compound and WMB compounds.

\begin{tabular}{ccc}
\hline Mixing time (min:sec) & \multicolumn{2}{c}{ Action of SMB step } \\
\hline Compound type & DMB & WMB \\
\hline $0: 00$ & Add rubber & Add WMB \\
$0: 40$ & Add 1/2 silica, 1/2 TESPT & - \\
$1: 40$ & Add 1/2 silica, 1/2 TESPT & Sweep \\
$3: 40$ & Add ZnO, St /A, 6PPD \\
$5: 40$ & Dump \\
$12: 00$ & Action of FMB step \\
& Add SMB \\
$0: 00$ & Add sulfur, cure accelerators \\
$2: 00$ & Dump \\
\hline
\end{tabular}

\subsubsection{Analysis of Uncured Compounds}

The bound rubber content was measured to determine the degree of F-R interaction, we prepared 4 samples of each per 1 compound then obtained average bound rubber contents (\%) by bound rubber analysis. In detail, bound rubber content was measured by adding $0.2 \mathrm{~g}$ of unvulcanized rubber compound to 200 mesh wire net and storing in a vial containing $200 \mathrm{~mL}$ of toluene for six days. The toluene was replaced once on the third day. After that, the solvent was replaced with acetone to remove the toluene and stored for $24 \mathrm{~h}$. Then, the mass was measured after drying in an oven at $10.5^{\circ} \mathrm{C}$ for $24 \mathrm{~h}$. The measured weight was substituted into Equation (4) to calculate the bound rubber content.

$$
R_{\mathrm{b}}(\%)=\frac{W_{\mathrm{fg}}-W_{\mathrm{t}}\left[\frac{m_{\mathrm{f}}}{m_{\mathrm{f}}+m_{\mathrm{r}}}\right]}{W_{\mathrm{t}}\left[\frac{m_{\mathrm{r}}}{m_{\mathrm{f}}+m_{\mathrm{r}}}\right]} * 100
$$

where $R_{\mathrm{b}}$ is the bound rubber content (\%), $W_{\mathrm{fg}}$ is the weight of the filler and gel, $W_{\mathrm{t}}$ is the weight of the sample before immersion, $\mathrm{m}_{\mathrm{f}}$ is the weight fraction of the filler in the compound, and $m_{\mathrm{r}}$ is the weight fraction of rubber in the compound.

The Moony viscosity was measured 2 times according to ASTM D 1646 using a Moony viscometer (Vluchem IND, Siheung, Korea). In detail, samples were preheated for $1 \mathrm{~min}$ at $10{ }^{\circ} \mathrm{C}$ and then rotated for 4 min at $2 \mathrm{RPM}$ at $100^{\circ} \mathrm{C}$. The Payne effect, which is an index of silica dispersibility, was measured according to ASTM D 8059 using a rubber process analyzer (RPA 2000, Alpha Technologies, Hudson, $\mathrm{OH}, \mathrm{USA}$ ), based on the results of a study by the Dutch Society of Plastic and Rubber Technologists [30]. The Payne effect was calculated using the $G^{\prime}$ value at a strain interval of $1.8-31.7 \%$.

\subsubsection{Analysis of WMB and DMB Vulcanizates}

The sheeted FMB compound prepared by a two-roll mill, which was tested to analyze the cure characteristics using a moving die rheometer (MDR, TOYOSEIKI, Tokyo, Japan) for $30 \mathrm{~min}$ at $160^{\circ} \mathrm{C}$ with vibration conditions of $\pm 1^{\circ}$. The cure rate was calculated using the measured values, and the vulcanization was carried out at $160^{\circ} \mathrm{C}$ for the measured cure characteristics.

To measure the crosslinking density of the vulcanized compounds, they were cut into dimensions of $10 \mathrm{~mm} \times 10 \mathrm{~mm}$ and stored in a vial containing tetrahydrofuran (THF, $50 \mathrm{~mL}$ ) for $48 \mathrm{~h}$. The sample was then treated with $\mathrm{n}$-hexane $(50 \mathrm{~mL})$ for $48 \mathrm{~h}$ to remove organic chemicals. After drying for two days at room temperature, the mass of the sample was measured, and then the weight was measured by swelling in toluene for $48 \mathrm{~h}$. The measured weight values were substituted into Equation (5) to calculate the crosslink density.

$$
v=\frac{1}{2 M_{\mathrm{c}}}=-\frac{\ln \left(1-V_{1}\right)+V_{1}+\chi V_{1}^{2}}{2 \rho_{\mathrm{r}} V_{0}\left(V_{1}^{\frac{1}{3}}-\frac{V_{1}}{2}\right)}
$$


where $v$ is the crosslink density $\left(\mathrm{mol} \cdot \mathrm{g}^{-1}\right), M_{\mathrm{c}}$ is the average molecular weight between crosslink points $\left(\mathrm{g} \cdot \mathrm{mol}^{-1}\right), V_{1}$ is the volume fraction of rubber in the swollen gel at equilibrium, $V_{0}$ is the molar volume of solvent $\left(\mathrm{cm}^{3} \cdot \mathrm{mol}^{-1}\right), \rho_{\mathrm{r}}$ is the density of the rubber sample $\left(\mathrm{g} \cdot \mathrm{cm}^{-3}\right)$, and $\chi$ is the polymer-solvent interaction parameter.

To measure the mechanical properties of the vulcanizates, 3 specimens per each compound were prepared according to ASTM D 412 and evaluated using a universal testing machine (UTM, KSU Co., Seoul, South Korea). The abrasion resistance was evaluated with a DIN abrasion tester (KSU Co., Korea) according to ASTM D 5963. Four specimens per each compound were manufactured in a cylindrical shape with a diameter of $16 \mathrm{~mm}$ and a thickness of $8 \mathrm{~mm}$ and the mass change of the specimens was measured by abrading the specimen with $40 \mathrm{~m}$ under a vertical load of $5 \mathrm{~N}$ using a cylindrical drum with a polishing cloth.

The dynamic viscoelastic properties of the vulcanizates were measured according to ASTM D 4065 using a dynamic mechanical thermal analyzer (EPLEXOR 500 N, GABO, Ahlden, Germany) under the temperature range of -80 to $80^{\circ} \mathrm{C}$. The glass transition temperature $\left(T_{\mathrm{g}}\right)$, $\tan \delta$ at $0{ }^{\circ} \mathrm{C}$ (wet traction index), and $\tan \delta$ at $60^{\circ} \mathrm{C}$ (rolling resistance index) were measured.

\section{Results and Discussion}

\subsection{Hydrophobation of TESPT-Modified Silica}

Table 4 shows the results of hydrophobation of surface-modified silica according to TESPT content. As the TESPT content increased, the hydrophobation of silica also increased, but the reaction efficiency decreased. This is due to the steric hindrance caused by the previously reacted TESPT molecules when the incoming TESPT reacts with the silanol groups on the silica surface [31]. Therefore, in this study, $12 \%$ TESPT-modified silica was used in subsequent experiments, because $10 \%$ TESPT silica showed lower hydrophobation than 12\% TESPT silica. Also, 15\% TESPT silica showed higher hydrophobation than $12 \%$ TESPT silica, but it had shown low efficiency for hydrophobation.

Table 4. Degree of hydrophobation of the modified silica according to the content of TESPT.

\begin{tabular}{ccccccc}
\hline Silica types & Without silica & Pure silica & $\mathbf{8 \%}$ TESPT & $\mathbf{1 0 \%}$ TESPT & $\mathbf{1 2 \%}$ TESPT & $\mathbf{1 5 \%}$ TESPT \\
\hline Acid-base titration & 2.22 & 0.95 & 1.25 & 1.68 & 1.85 & 1.91 \\
solution amount $(\mathrm{mL})$ & - & 0 & 23.6 & 57.5 & 70.9 & 75.6 \\
Hydrophobation $(\%)$ & & &
\end{tabular}

\subsection{Silica Content and $p H$ of ESBR/Silica WMBs}

The $\mathrm{pH}$ values of ESBR/silica WMB prepared using different types of coagulants were indirectly measured and the results are shown in Table 5. As a result, ESBR/silica WMB with sulfuric acid solution alone showed the lowest $\mathrm{pH}$ value, and $\mathrm{WMB}$ with the mixture of sodium chloride solution and sulfuric acid solution was lower than 7 . This is the result of the $\mathrm{pH}$ being lowered by residual sulfuric acid and the fatty acid $(\mathrm{R}-\mathrm{COOH})$, the reaction product of the surfactant and coagulant shown in Figure 2. WMB T-4, which used the calcium chloride solution, showed a $\mathrm{pH}$ value higher than 7 since a compound of calcium carboxylate $\left((\mathrm{R}-\mathrm{COO})_{2} \mathrm{Ca}\right)$ is formed without generating a fatty acid type compound when a coagulant and an emulsifier are reacted.

Table 5. $\mathrm{pH}$ value of WMBs according to the coagulant type.

\begin{tabular}{cccc}
\hline $\begin{array}{c}\text { WMB code } \\
\text { (Coagulant) }\end{array}$ & $\begin{array}{c}\text { WMB T-2 } \\
\left(\mathbf{H}_{2} \mathrm{SO}_{4}\right)\end{array}$ & $\begin{array}{c}\text { WMB T-3 } \\
\left(\mathbf{N a C l}+\mathbf{H}_{\mathbf{2}} \mathbf{S O}_{4}\right)\end{array}$ & $\begin{array}{c}\text { WMB T-4 } \\
\left(\mathrm{CaCl}_{\mathbf{2}}\right)\end{array}$ \\
\hline $\mathrm{pH}$ & 5.5 & 6.4 & 7.7 \\
\hline
\end{tabular}




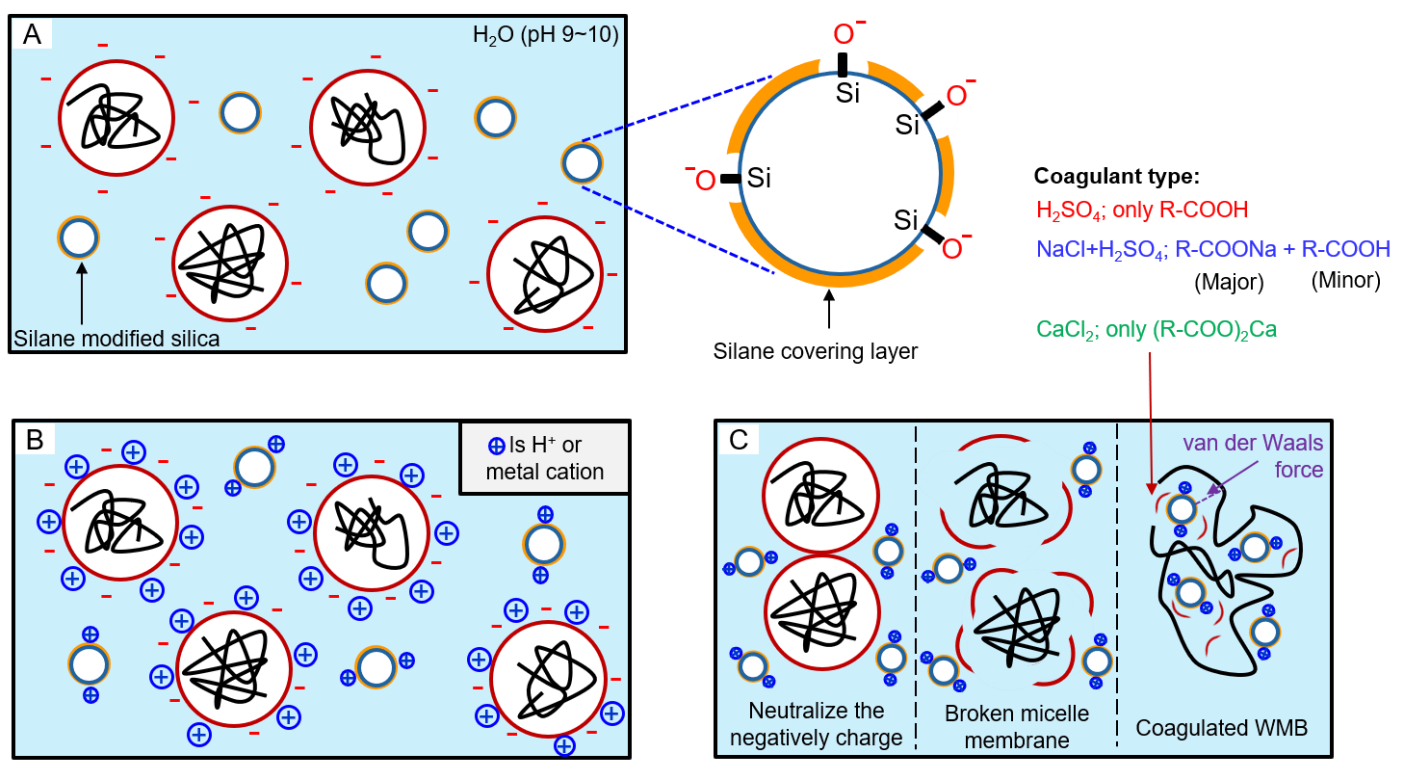

Figure 2. Illustration of the reaction among surface-modified silica, surfactant, and coagulant during WMB manufacturing process: (A) a state in which micelles and modified silica having a negative charge surface are dispersed in water, $(\mathbf{B})$ a state after coagulants were added, and (C) a state in which modified silica and ESBR were coagulated. Also, by-products between emulsifier and cation remained, for example, carboxy acid, sodium carboxylate, and calcium carboxylate, according to the coagulant type.

The silica content of ESBR/silica WMB was analyzed by TGA, and the results are shown in Table 6 and Figure S1. As a result of the evaluation, WMB T-4, which used a calcium chloride aqueous solution containing a divalent metal atom as a coagulant, showed the highest silica content. When ESBR/silica WMB is manufactured, surface-modified silica and ESBR were coagulated due to van der Waals force [32]. Therefore, the higher degree of silica hydrophobation cause the higher silica content of ESBR/silica WMB.

When the calcium chloride solution is applied as a coagulant in the basic condition, the hydrogen of the unreacted silanol group on the silica surface is removed in basic condition, then calcium cation reacted with $\mathrm{SiO}^{-}$on the silica surface. As a result, the silica surface is more hydrophobized by the alkali-silica reaction and the reaction between the emulsifier and coagulant, as shown in Figure $4[29,33]$. The second highest result was obtained in the WMB T-3. Since the $\mathrm{Na}^{+}$ion is a monovalent cation, thus has lower reactivity with the silanol group than the $\mathrm{Ca}^{2+}$ ion $[33,34]$.

When sulfuric acid was applied alone, the alkali-silica reaction could not take place, and the silanol group remained as it was, thus showing the lowest silica content.

Table 6. Silica content in the ESBR WMB according to the type of coagulant.

\begin{tabular}{cccc}
\hline WMBs & WMB T-2 $\left(\mathbf{H}_{\mathbf{2}} \mathbf{S O} \mathbf{O}_{\mathbf{4}}\right)$ & WMB T-3 $\left(\mathbf{N a C l}+\mathbf{H}_{\mathbf{2}} \mathbf{S O} \mathbf{O}_{\mathbf{4}}\right)$ & $\mathbf{W M B ~ T - 4}\left(\mathbf{C a C l}_{\mathbf{2}}\right)$ \\
\hline Ash (wt \%) & 35.1 & 35.7 & 36.4 \\
SBR (wt \%) & 48.0 & 48.4 & 47.7 \\
Silica content (phr) & 73.1 & 73.8 & 76.3 \\
Silica loss (\%) & 8.6 & 7.8 & 4.6 \\
\hline
\end{tabular}

\subsection{Analysis of Uncured Compounds}

Figure 3 and Table 7 show the results of the Mooney viscosity $\left(\mathrm{ML}_{1+4} @ 100{ }^{\circ} \mathrm{C}\right)$ and Payne effect $\left(\Delta G^{\prime}, G_{\text {initial }}-G_{\text {final }}\right)$ analysis, which is a measure of processability and silica dispersion in compounds. Generally, low $\mathrm{ML}_{1+4} @ 100{ }^{\circ} \mathrm{C}$ value and low $\Delta G^{\prime}$ value show good processability because of the good silica dispersion $[30,35,36]$. The ESBR/silica WMB compound showed lower Mooney viscosity than 
the DMB compound. As shown in Figure 4, Mooney viscosity results caused by the lubricant role of the aforementioned metal carboxylate compounds and the increased hydrophobation of the silica due to the alkali-silica reaction.

The results of the Payne effect also show that the ESBR/silica WMB compound exhibits lower $\Delta G^{\prime}$ value than DMB compound. In particular, the lowest $\Delta G^{\prime}$ value occurs when calcium chloride is added due to the increased hydrophobation of the silica via the alkali-silica reaction. Combining the results of the two analyses, WMB compounds showed good silica dispersion; in particular, the WMB compound showed the best silica dispersion in the compound using calcium chloride as a coagulant.

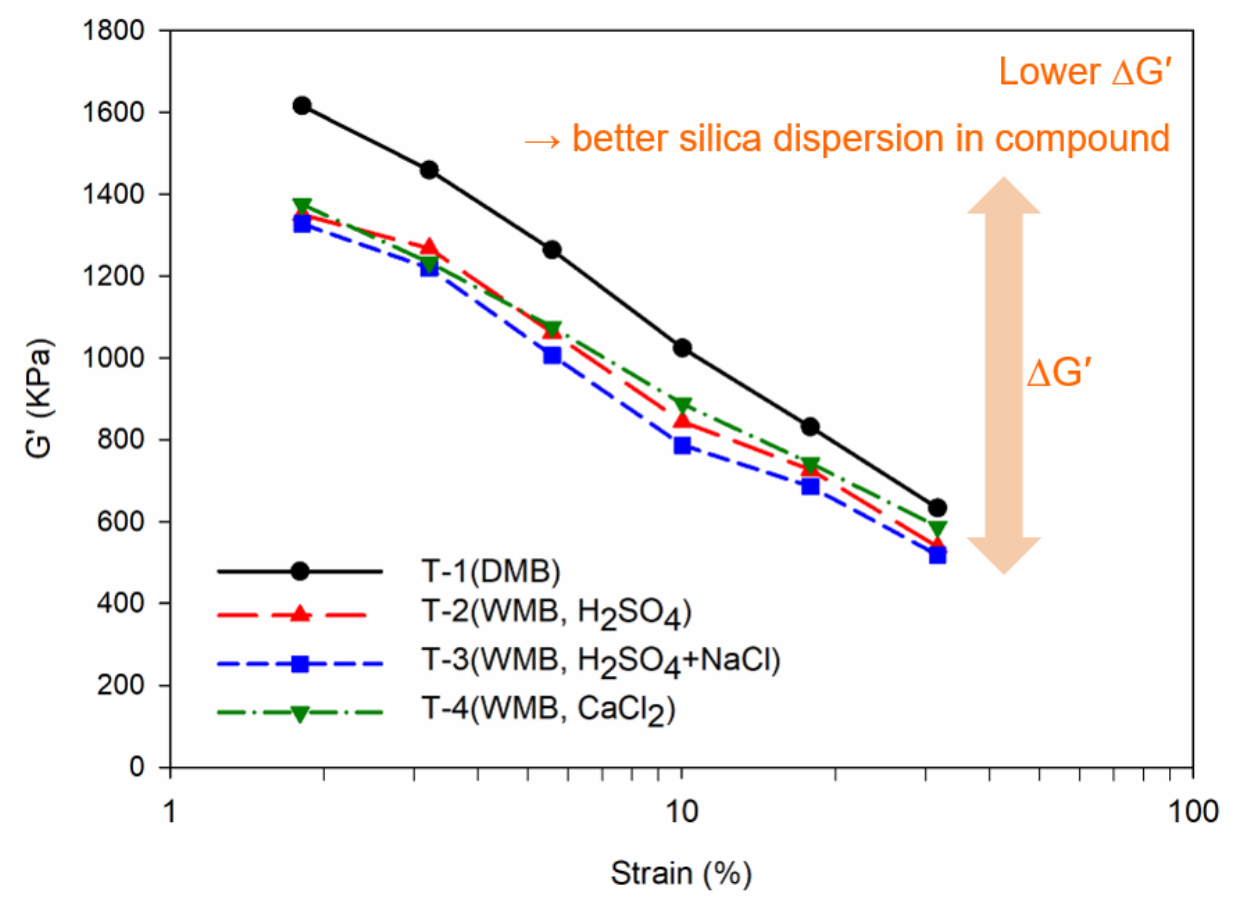

Figure 3. Payne effect $\left(\Delta G^{\prime}\right)$ of the T-1 to T-4 compounds, which mean degree of filler dispersion in a compound: the black line graph is the Payne effect result of the T-1 DMB compound, the red line is the Payne effect result of the T-2 WMB compound, the blue line is the Payne effect result of the T-3 WMB compound, and the green line is the Payne effect result of the T-4 WMB compound.

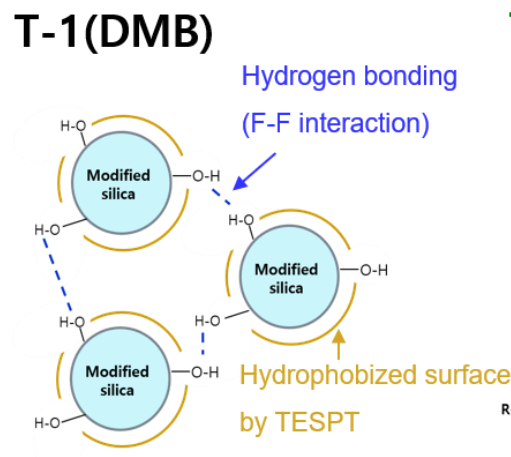

(A)

\section{T-4(WMB, $\mathrm{CaCl}_{2}$ )}

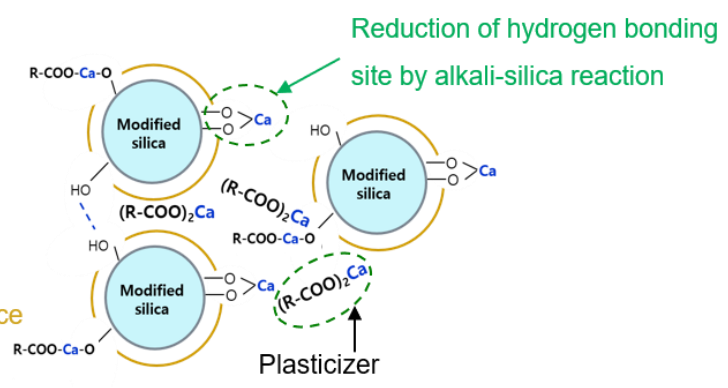

(B)

Figure 4. Illustration of expected filler network structure in the silica filled compounds: (A) the T-1 (DMB) compound, which has a residue silanol group and interaction between silica by hydrogen bonding and (B) The T-4 WMB compound using $\mathrm{CaCl}_{2}$, which has fewer silanol groups than the DMB compound by alkali-silica reaction. 
Table 7. Payne effect $\left(\Delta G^{\prime}\right)$ and Mooney viscosity $\left(\mathrm{ML}_{1+4} @ 100{ }^{\circ} \mathrm{C}\right)$ of the T- 1 to T- 4 compounds.

\begin{tabular}{ccccc}
\hline Compounds & T-1 & T-2 & T-3 & T-4 \\
\hline Coagulant type & - & $\mathrm{H}_{2} \mathrm{SO}_{4}$ & $\mathrm{H}_{2} \mathrm{SO}_{4}+\mathrm{NaCl}$ & $\mathrm{CaCl}_{2}$ \\
$\Delta G^{\prime}(\mathrm{KPa})\left(G^{\prime}\right.$ at $1.8 \%$ strain $-G^{\prime}$ at $31.7 \%$ strain $)$ & 983.1 & 812.0 & 810.0 & 788.1 \\
$\mathrm{ML}_{1+4} @ 100{ }^{\circ} \mathrm{C}$ & 114 & 107 & 104 & 103 \\
\hline
\end{tabular}

Bound rubber measurement results are shown in Table 8. The T-4 compound with calcium chloride as a coagulant showed high bound rubber content and showed excellent results with respect to the F-R interaction. The F-R interaction is improved as the hydrophobation of the silica is increased by the alkali-silica reaction. However, T-2 and T-3 compounds containing sulfuric acid showed lower bound rubber content than the DMB compound, which was disadvantageous in the F-R interaction.

Table 8. Bound rubber content of the T-1 to T-4 compounds.

\begin{tabular}{ccccc}
\hline Compounds & T-1 & T-2 & T-3 & T-4 \\
\hline Bound rubber $(\%)$ & 31.3 & 29.5 & 28.5 & 36.6 \\
\hline
\end{tabular}

\subsection{Characterization of Ca-Coated TESPT-Modified Silica}

Table 9 shows the hydrophobation results of Ca-coated 12 wt \% TESPT-modified silica by DBA adsorption and the calcium content analysis by XRF. The Ca-coated $12 \mathrm{wt} \%$ TESPT-modified silica showed a $10 \%$ increase in hydrophobation compared to the conventional $12 \mathrm{wt} \%$ modified silica, and the calcium content of the silica increased by 14 times after the actual calcium treatment. These results showed by alkali-silica reaction between remaining silanol groups on the surface of TESPT modified silica and Ca cation from calcium hydroxide. Thus, the concentration of hydrogen atom decreased on the Ca-coated modified silica surface, and active sites for hydrogen bonding reduced. It caused a higher hydrophobation value than that of un-coated TESPT modified silica. Therefore, the alkali-silica reaction between silanol groups and calcium ions will occur under similar conditions in ESBR/silica WMB using calcium chloride as a coagulant, which results in excellent silica dispersion in the ESBR/silica WMB compound.

Table 9. Hydrophobation and calcium content according to the type of modified silica.

\begin{tabular}{cccc}
\hline Silica type & $\begin{array}{c}\text { Pure silica } \\
\text { (un-modified) }\end{array}$ & $\begin{array}{c}\text { 12 wt \% TESPT } \\
\text { modified silica }\end{array}$ & $\begin{array}{c}\text { Ca-coated 12 wt \% } \\
\text { TESPT-silica }\end{array}$ \\
\hline $\begin{array}{c}\text { Hydrophobation }(\%) \\
\text { Ca atom content by XRF }(\%)\end{array}$ & 0 & 70.9 & 81.0 \\
\hline
\end{tabular}

\subsection{Cure Characteristics and Crosslink Density}

The results of the measurement of the cure characteristics and the crosslink density of the vulcanizates are shown in Figure 5 and Table 10. As a result, the WMB compound showed a lower $T_{\max }$ value and delta torque $\left(T_{\max }-T_{\min }\right)$ value than the DMB compound. It was found that the metal carboxylate or fatty acid compound formed by the reaction between coagulant and surfactant acted as a lubricant [37]. In the case of the T-2 and T-3 compounds using sulfuric acid as a coagulant, the activity of the accelerator declined due to the acid-base reaction of residual sulfuric acid and accelerator, resulting in a slow cure rate compared with that of the DMB compound. However, when calcium chloride was added, the acid-base reaction does not occur with the accelerator because there is no residual acid. Adsorption loss due to the silanol group was also low as the hydrophobation further increased through the alkali-silica reaction, indicating that the cure rate was faster than that of the DMB compound.

As a result of the crosslink density measurement, the crosslink density values of the WMB compounds were lower than that of the DMB compound. This is because the crosslink density of the 
ESBR WMB compound using a sulfuric acid coagulant was decreased by residual sulfuric acid, and that of the WMB compound using calcium chloride was decreased by the metal carboxylate compound. According to the results of the study of calcium carboxylate added to rubber compounds $[37,38]$, calcium stearate added at $0.5 \mathrm{phr}$ improved the dispersion and mechanical properties of silica. However, the addition of more than $0.5 \mathrm{phr}$ of calcium stearate inhibited the reaction of $\mathrm{ZnO}$, resulting in decreased crosslink density. Therefore, in this ESBR/silica WMB manufacturing process, the surfactant reacts with calcium ions to produce a calcium carboxylate compound in the form of a similar calcium stearate. Therefore, it is considered that the produced calcium carboxylate compound is present in the rubber compound at $0.5 \mathrm{phr}$ or more.

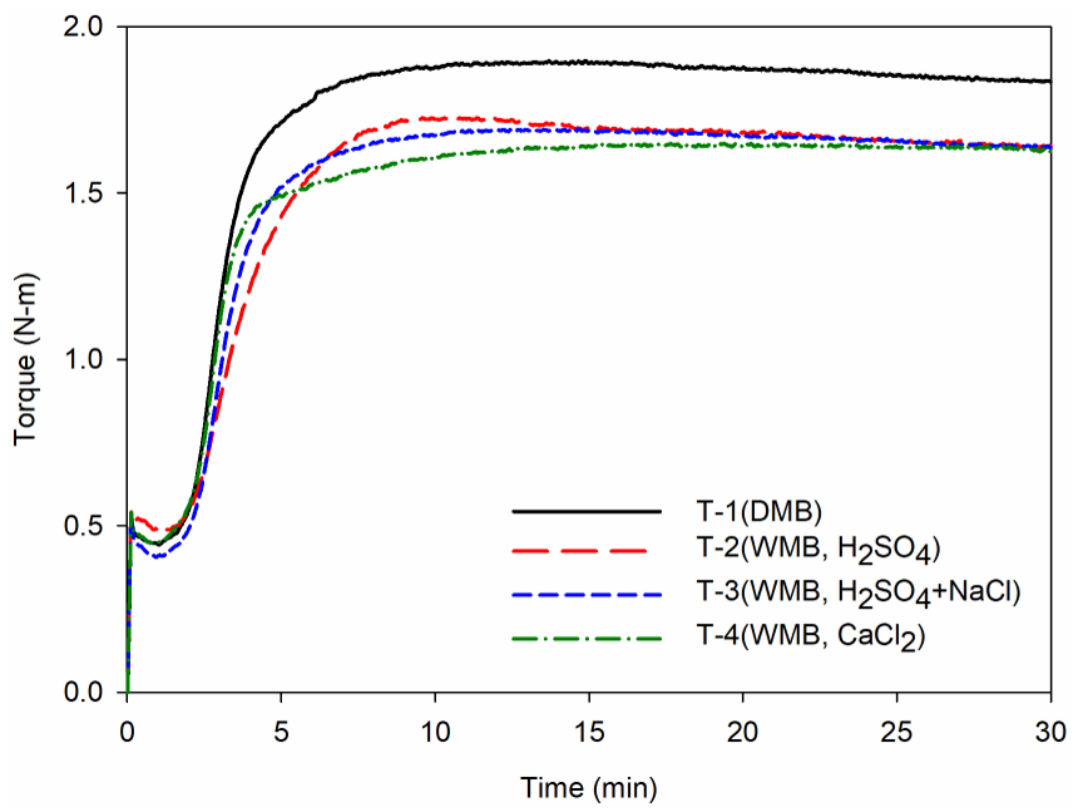

Figure 5. Cure characteristics of the T-1 to T-4 compounds: Each graph shows cure characteristics behavior of compounds according to the cure time. The black line shows the cure behavior of the T-1 DMB compound, the red line shows the T-2 WMB compound, the blue line shows the T- $3 \mathrm{WMB}$ compound, and the green line shows the T-4 WMB compound.

Table 10. Cure characteristics and crosslink density of the T-1 to T-4 compounds.

\begin{tabular}{cccccc}
\hline \multicolumn{2}{c}{ Compounds } & T-1 & T-2 & T-3 & T-4 \\
\hline$t_{10}$ & min:sec & $3: 32$ & $2: 17$ & $2: 10$ & $2: 02$ \\
$t_{90}$ & min:sec & $5: 35$ & $6: 27$ & $5: 38$ & $6: 02$ \\
Cure rate & $\mathrm{N}-\mathrm{m} \cdot \mathrm{min}^{-1}$ & 0.656 & 0.325 & 0.512 & 0.690 \\
$T_{\min }$ & $\mathrm{N}-\mathrm{m}$ & 0.444 & 0.483 & 0.406 & 0.449 \\
$T_{\max }$ & $\mathrm{N}-\mathrm{m}$ & 1.898 & 1.726 & 1.694 & 1.649 \\
$T_{\max }-T_{\min }$ & $\mathrm{N}-\mathrm{m}$ & 1.454 & 1.243 & 1.288 & 1.200 \\
\hline Crosslink density & $10^{-4} \mathrm{~mol} \cdot \mathrm{g}^{-1}$ & 1.2178 & 1.1128 & 1.1504 & 1.1446 \\
\hline
\end{tabular}

\subsection{Mechanical Properties and DIN Abrasion of T-1 to T-4 Vulcanizates}

The mechanical properties are shown in Figure 6 and Table 11. The 100\% modulus exhibits a higher value when the silica dispersion is poor. Therefore, when comparing the T-3 and T- 4 compounds, the T-4 compound shows a low 100\% modulus, confirming the excellent silica dispersion. The T-1 compound with the highest crosslink density showed the highest $300 \%$ modulus. The T- 3 and $\mathrm{T}-4$ compounds showed similar crosslinking densities, but as the T- 4 compound had excellent F-R interaction, the $300 \%$ modulus for the T- 4 compound was better. The T-2 compound showed the most unfavorable value due to the low crosslink density and F-R interaction. In the mechanical properties 
test, the value obtained by dividing the $300 \%$ modulus by the $100 \%$ modulus is called a reinforcement effect and is used as a measure of F-R interaction on mechanical properties. The results show that the $\mathrm{T}-4$ compound has the highest value, which is consistent with the results of the bound rubber content evaluation. Tensile strength and elongation were found to be similar for all compounds.

The DIN abrasion test showed that the T-4 compound had the best value to support the bound rubber test result and the reinforcing effect calculation result. The DMB compound, T-1, also showed good results. The T-2 and T-3 compounds have a more adverse result than T-1 compounds in the same way as the outcome trends in the bound rubber content, in particular, T-2, a compound using sulfuric acid alone, had the least favorable results due to its low crosslink density.

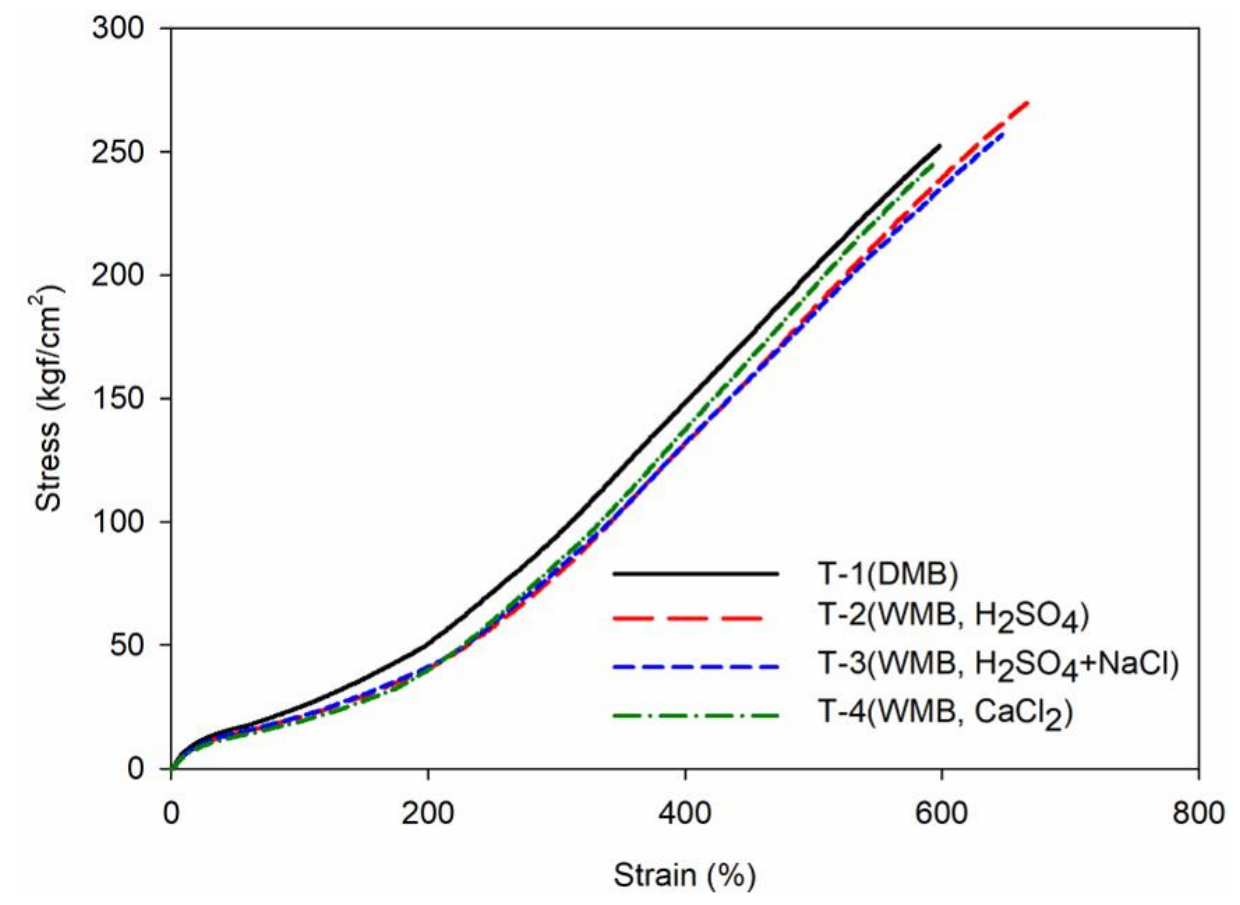

Figure 6. Mechanical properties of the T-1 to T-4 compounds: the black line shows the mechanical property of the DMB T-1 compound, the red line shows the mechanical property of the WMB T-2 compound, the blue line shows the mechanical property of the WMB T-3 compound, and the green line shows the mechanical property of the WMB T-4 compound.

Table 11. Mechanical properties and DIN abrasion of the T-1 to T-4 compounds.

\begin{tabular}{cccccc}
\hline Compounds & Unit & T-1 & T-2 & T-3 & T-4 \\
\hline$M_{100 \%}$ & $\mathrm{kgf} \cdot \mathrm{cm}^{-2}$ & 24.8 & 20.8 & 21.0 & 18.9 \\
$M_{300 \%}$ & $\mathrm{kgf} \cdot \mathrm{cm}^{-2}$ & 94.1 & 78.5 & 80.3 & 83.4 \\
$M_{300 \%} / M_{100 \%}$ & - & 3.79 & 3.77 & 3.82 & 4.41 \\
Elongation at break & $\%$ & 600 & 670 & 650 & 590 \\
Tensile strength & $\mathrm{kgf} \cdot \mathrm{cm}^{-2}$ & 252 & 270 & 257 & 244 \\
\hline DIN abrasion & $\mathrm{mg}$ & 115.1 & 120.5 & 118.2 & 114.0 \\
\hline
\end{tabular}

\subsection{Viscoelastic Properties of T-1 to T-4 Vulcanizates}

The results of dynamic viscoelastic properties are shown in Figure 7 and Table 12. Since only the type of coagulant was different and ESBR with the same microstructure was used in all cases, the glass transition temperature of the compound was measured to be almost the same for all samples. The value of $\tan \delta$ at the glass transition temperature is higher when the dispersion of silica is better [31]. Therefore, the T-4 compound, which had the highest silica dispersion in Payne effect and Mooney viscosity measurements, showed the highest $\tan \delta$ value at $T_{\mathrm{g}}$. In addition, the T-2 and T-3 compounds, 
both which were made using the WMB technology, showed excellent silica dispersion compared with the DMB compound, $\mathrm{T}-1$. The value of $\tan \delta$ at $0{ }^{\circ} \mathrm{C}$, all compound showed similar results.

The value of $\tan \delta$ at $60^{\circ} \mathrm{C}$, which is a measure of rolling resistance during driving, generally shows a lower value as the crosslinking density is higher [39]. As a result, the DMB compound, $\mathrm{T}-1$, showed the lowest value, and excellent results were obtained. The T-4 compound had a low crosslinking density compared with T-1 but had a similar rolling resistance because of the good silica dispersion and excellent F-R interaction. The results suggest that the use of calcium chloride in the WMB technology results in a lower total crosslink density than the DMB applied compound. However, as the degree of hydrophobation of the silica increases, the excellent silica dispersion and the improved filler-rubber interaction complement the low crosslinking density, showing dynamic viscoelastic properties similar to the DMB compound.

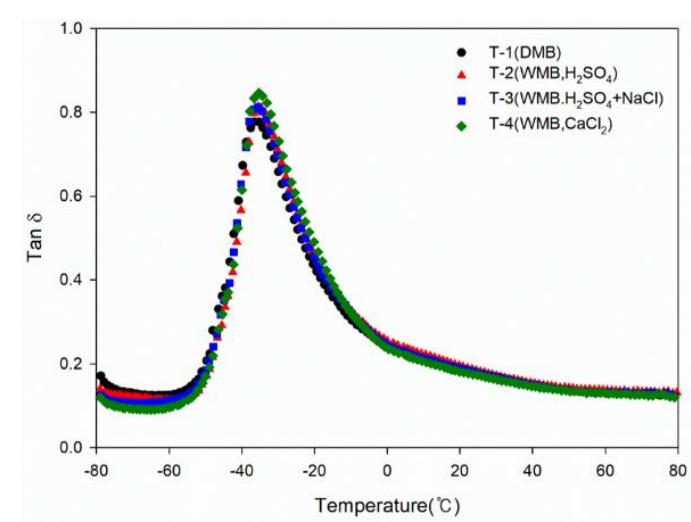

(A)

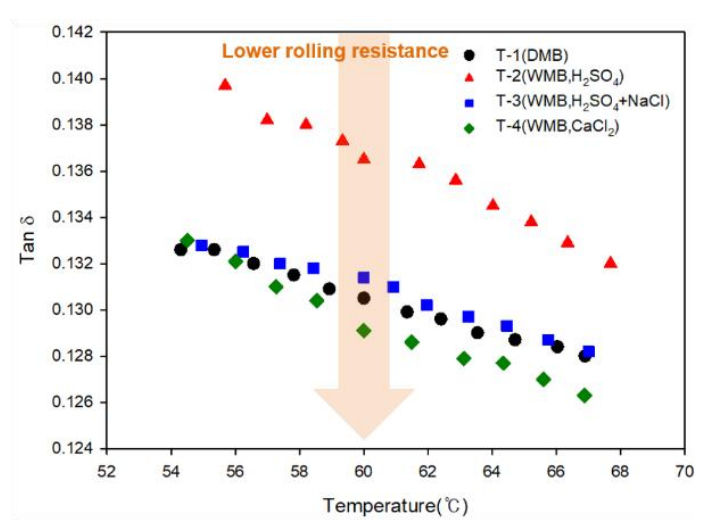

(B)

Figure 7. Tan $\delta$ graphs of the T- 1 to T- 4 compounds as a function of temperature: (A) from -80 to $80{ }^{\circ} \mathrm{C}$ and (B) from 54 to $68^{\circ} \mathrm{C}$. These graphs show that rolling resistance and wet traction performance: the black color symbol shows the hysteresis behavior of the T-1 DMB compound, the red symbol shows the hysteresis behavior of the T-2 WMB compound, the blue symbol shows the hysteresis behavior of the T-3 WMB compound, and the green symbol shows the hysteresis behavior of the T-4 WMB compound.

Table 12. Viscoelastic properties of the T-1 to T-4 compounds.

\begin{tabular}{ccccc}
\hline Compounds & T-1 & T-2 & T-3 & T-4 \\
\hline Coagulant type & - & $\mathrm{H}_{2} \mathrm{SO}_{4}$ & $\mathrm{H}_{2} \mathrm{SO}_{4}+\mathrm{NaCl}$ & $\mathrm{CaCl}_{2}$ \\
$T_{\mathrm{g}}\left({ }^{\circ} \mathrm{C}\right)$ & -35.3 & -35.3 & -35.6 & -35.6 \\
$\tan \delta$ at $T_{\mathrm{g}}$ & 0.7772 & 0.8134 & 0.8122 & 0.8461 \\
$\tan \delta$ at $0{ }^{\circ} \mathrm{C}$ & 0.2452 & 0.2536 & 0.2430 & 0.2369 \\
Wet traction index $(\%)$ & 100 & 103 & 99 & 97 \\
$\tan \delta$ at $60{ }^{\circ} \mathrm{C}$ & 0.1305 & 0.1365 & 0.1314 & 0.1291 \\
Rolling resistance index $(\%)$ & 100.0 & 95.6 & 99.3 & 101.8 \\
\hline
\end{tabular}

\section{Conclusions}

The results of the analysis of silica content in ESBR/silica WMB using TGA confirmed that the silica content was $4 \%$ increased than other coagulants when alkali metal ions were present in the coagulant, leading to increased $10.1 \%$ hydrophobation of the silica by the alkali-silica reaction.

From the results of the Payne effect measurements, it was confirmed that the ESBR/silica WMB applied compounds had a high silica dispersibility, in particular T-4 compound was improved by $25 \%$ than T-1 DMB compound when calcium chloride was used as a coagulant. Also, Mooney viscosity results showed lowest value $\left(\mathrm{ML}_{1+4} @ 100{ }^{\circ} \mathrm{C}: 103\right)$ when calcium chloride was used, confirming the excellent silica dispersion. This occurred because the surfactant constituting the micelle in the rubber latex remained after the reaction with the coagulant, thereby acting as a processing aid and increasing the silica hydrophobation through the alkali-silica reaction. Bound rubber measurements showed more 
$5 \%$ bound rubber content than other compound when the WMB compound using calcium chloride due to the better hydrophobation of silica.

Measuring various properties of the vulcanizate showed that the T-2 and T-3 compounds had a loss of accelerator activity due to an acid-base reaction between residual sulfuric acid and residual emulsifier, which decreased the crosslink density. This lower crosslink density was a disadvantage compared with the WMB compound made with calcium chloride with respect to the mechanical properties, dynamic viscoelastic properties, and abrasion resistance. The T-4 compound, a WMB compound with calcium chloride, showed excellent physical properties compared with other coagulants, but the $300 \%$ modulus was $11 \%$ lower than that of the DMB compound due to the lower crosslink density because of residual calcium carboxylate. However, the high F-R interaction measured in the bound rubber test, the Payne effect, and the excellent silica dispersion measured in the Mooney viscosity test complement the properties of the WMB compound, thus exhibiting abrasion resistance and rolling resistance characteristics $\left(\tan \delta\right.$ at $60^{\circ} \mathrm{C}$ ) similar to the DMB compound.

The above results confirmed that calcium chloride was an excellent coagulant when ESBR/silica WMB was manufactured. However, the low crosslink density compared with that of the DMB compound was problematic. If this problem is solved, the WMB compound is expected to show improved the properties, dynamic viscoelastic properties, and abrasion resistance as a result of the excellent silica dispersion and F-R interaction compared with those of the DMB compound. In order to improve crosslink density, we will apply the alcohol washing process during the manufacturing process of ESBR/silica WMB to minimize residue calcium carboxylate. Also, the recovery process of waste water, organic solvent, and lost silica in the manufacturing process of ESBR/silica WMB should be studied for commercialization and optimization in plant processes [40,41].

Supplementary Materials: The supplementary materials are available online at http:/ /www.mdpi.com/20734360/10/10/1116/s1. Figure S1. TGA thermogram for the silica content in the WMBs depending on the coagulant type. In each graph, it is possible to confirm that TDAE oil, ESBR and TESPT are burned as the temperature rises, and the silica content in WMB can be estimated through the content of the remaining ash: Red line is a thermogram of WMB T-2 used $\mathrm{H}_{2} \mathrm{SO}_{4}$ coagulant, blue line is a thermogram of WMB T-3 used $\mathrm{NaCl}+\mathrm{H}_{2} \mathrm{SO}_{4}$, and green line is a thermogram of WMB T-4 used $\mathrm{CaCl}_{2}$.

Author Contributions: Conceptualization, W.K. (Wonho Kim), W.K. (Woong Kim); data curation, W.K. (Woong Kim); investigation, E.Y., G.R.; formal analysis, B.A., D.K.; Visualization, H.M., K.H.; project administration, W.K. (Wonho Kim); Supervision, W.K. (Wonho Kim); Writing-original draft, W.K. (Woong Kim).

Funding: This work was supported by Minister of Trade, Industry and Energy Grant funded by the Korean Government [Project Number 10067128] and BK21 PLUS Centre for Advanced Chemical Technology [21A20131800002], Republic of Korea.

Conflicts of Interest: The authors declare no conflict of interest.

\section{References}

1. Hall, D.E.; Moreland, J.C. Fundamentals of rolling resistance. Rubber Chem. Technol. 2001, 74, 525-539. [CrossRef]

2. Pillai, P.S.; Fielding-Russell, G.S. Tire rolling resistance from whole-tire hysteresis ratio. Rubber Chem. Technol. 1992, 65, 444-452. [CrossRef]

3. Nikiel, L.; Gerspacher, M.; Yang, H.; O'Farrell, C.P. Filler dispersion, network density, and tire rolling resistance. Rubber Chem. Technol. 2001, 74, 249-259. [CrossRef]

4. Takino, H.; Nakayama, R.; Yamada, Y.; Kohjiya, S.; Matsuo, T. Viscoelastic properties of elastomers and tire wet skid resistance. Rubber Chem. Technol. 1997, 70, 584-594. [CrossRef]

5. Baker, C.S.L.; Gelling, I.R.; Newell, R. Epoxidized natural rubber. Rubber Chem. Technol. 1985, 58, 67-85. [CrossRef]

6. Wang, M.J. Effect of polymer-filler and filler-filler interactions on dynamic properties of filled vulcanizates. Rubber Chem. Technol. 1998, 71, 520-589. [CrossRef]

7. Kim, K.; Lee, J.Y.; Lim, S.H.; Kwag, G.H.; Paik, H.J; Kim, W. Effect of the amounts of glycidyl methacrylate on the mechanical and dynamic properties of styrene-butadiene-glycidyl methacrylate terpolymer/silica composites. Compos. Interfaces 2016, 23, 607-621. [CrossRef] 
8. Liu, X.; Zhao, S.; Zhang, X.; Li, X.; Bai, Y. Preparation, structure, and properties of solution-polymerized styrene-butadiene rubber with functionalized end-groups and its silica-filled composites. Polymers 2014, 55, 1964-1976. [CrossRef]

9. Hirzin, R.S.; Azzahari, A.D.; Yayha, R.; Hassan, A. Optimizing the usability of unwanted latex yield by in situ depolymerization and functionalization. Ind. Crops Prod. 2015, 74, 773-783. [CrossRef]

10. Kim, K.; Lee, J.Y.; Choi, B.J.; Seo, B.; Kwag, G.H.; Paik, H.J.; Kim, W. Styrene-butadiene-glycidyl methacrylate terpolymer/silica composites: Dispersion of silica particles and dynamic mechanical properties. Compos. Interfaces 2014, 21, 685-702. [CrossRef]

11. Nga Dang, T.T.; Kim, J.K.; Kim, K.J. Organo bifunctional silane effects on the vibration, thermal, and mechanical properties of a vinyl-group-containing silicone rubber/natural rubber/silica compound. J. Vinyl Addit. Technol. 2010, 16, 254-260. [CrossRef]

12. Choi, S.S. Influence of the silica content on rheological behaviour and cure characteristics of silica-filled styrene-butadiene rubber compounds. Polym. Int. 2001, 50, 524-530. [CrossRef]

13. Wang, Y.; Liao, L.; Zhong, J.; He, D.; Xu, K.; Yang, C.; Luo, Y.; Peng, Z. The behavior of natural rubber-epoxidized natural rubber-silica composites based on wet masterbatch technique. J. Appl. Polym. Sci. 2016, 133. [CrossRef]

14. Gui, Y.; Zheng, J.; Ye, X.; Han, D.; Xi, M.; Zhang, L. Preparation and performance of silica/SBR masterbatches with high silica loading by latex compounding method. Compos. Part B 2016, 85, 130-139. [CrossRef]

15. Wallen, P.J.; Bowman, G.C.; Colvin, H.A.; Hardiman, C.J.; Reyna, J.E.R. Processes for Making Silane, Hydrophobated Silica, Silica Masterbatch and Rubber Products. U.S. Patent 8,357,733, 22 January 2013.

16. Chen, Z.R.; Araki, S.; Cole, W.M.; Hergenrother, W.; Warren, S. Solution Masterbatch Process Using Fine Particle Silica for Low Hysteresis Rubber. U.S. Patent 7,312,271, 25 December 2007.

17. Prasertsri, S.; Rattanasom, N. Fumed and precipitated silica reinforced natural rubber composites prepared from latex system: Mechanical and dynamic properties. Polym. Test. 2012, 31, 593-605. [CrossRef]

18. Scholl, T.; Gladbach, B. Process for Production of Filled Rubber Mixtures. U.S. Patent 6,025,415, 15 February 2000.

19. Zhang, P.; Chen, S.L. Silica Containing Rubber Composition. U.S. Patent 7,307,121, 19 March 2004.

20. Zheng, J.; Ye, X.; Han, D.; Zhao, S.; Wu, X.; Wu, Y.; Dong, D.; Wang, Y.; Zhang, L. Silica Modified by Alcohol Polyoxyethylene Ether and Silane Coupling Agnet Together to Achieve High Performance Rubber Composites Using the Latex Compounding Method. Polymers 2018, 10, 1. [CrossRef]

21. Zheng, J.; Han, D.; Ye, X.; Wu, X.; Wu, Y.; Wang, Y.; Zhang, L. Chemical and physical interaction between silane coupling agent with long arms and silica and its effect on silica/natural rubber composites. Polymer 2018, 135, 200-210. [CrossRef]

22. He, F.; Yuan, T.; Li, C.; Sun, L.; Liao, S. Interfacial interactions and properties of natural rubber-silica composites with liquid natural rubber as a compatibilizer and prepared by a wet-compounding method. J. Appl. Polym. Sci. 2018, 135, 46457. [CrossRef]

23. Gilkman, S.A.; Korchagina, E.P. The Coagulation Mechanism of Butadiene-Styrene Latex. Rubber Chem. Technol. 1959, 31, 531-535. [CrossRef]

24. Ng, S.C.; Gan, L.H. Reaction of natural rubber latex with performic acid. Eur. Polym. J. 1981, 17, $1073-1077$. [CrossRef]

25. Martin, G.; Davey, W.S. Rubber from Latex Coagulated with Sulfuric Acid. Rubber Chem. Technol. 1935, 8, 274-283. [CrossRef]

26. Kim, W.; Ahn, B.; Moon, H.; Yu, E.; Hwang, K.; Kim, W. Evaluation of BR Blending Methods for ESBR/silica Wet Masterbatch Compounds. Elastomers Compos. 2017, 52, 242-248.

27. Araki, S.; Yanagisawa, K. Pneumatic Tires. U.S. Patent 6,022,923, 8 February 2000.

28. Okamoto, M.; Nobuhara, K.; Ishii, D. Effect of calcium-modified silica on retention and selectivity in normal-phase liquid chromatography. J. Chromatogr. A 1995, 697, 153-158. [CrossRef]

29. Hewitt, N.; Ciullo, P. Compounding Precipitated Silica in Elastomers: Theory and Practice; William Andrew: Norwich, NY, USA, 2007; pp. 16-18. ISBN 978-0-8155-1528-9.

30. Baaij, J. Measuring the Payne effect in filled rubber. In Proceedings of the VKRT Meeting, Weg naar Rhijnauwen, The Netherlands, 14 May 2009.

31. Li, Y.; Han, B.; Liu, L.; Zhang, F.; Zhang, L.; Wen, S.; Lu, Y.; Yang, H.; Shen, J. Surface modification of silica by two-step method and properties of solution styrene butadiene rubber (SSBR) nanocomposites filled with modified silica. Compos. Sci. Technol. 2013, 88, 69-75. [CrossRef] 
32. Sadek, E.M.; El-Nashar, D.E.; Ahmed, S.M. Effect of organoclay reinforcement on the curing characteristics and technological properties of styrene-butadiene rubber. Polym. Comp. 2015, 36, 1293-1302. [CrossRef]

33. Reta, M.; Carr, P.W. Comparative study of divalent metals and amines as silanol-blocking agents in reversed-phase liquid chromatography. J. Chromatogr. A 1999, 855, 121-127. [CrossRef]

34. Wang, H.; Gillott, J.E. Mechanism of alkali-silica reaction and the significance of calcium hydroxide. Cem. Concr. Res. 1991, 21, 647-654. [CrossRef]

35. Payne, A.R. Effect of dispersion on dynamic properties of filler-loaded rubbers. Rubber Chem. Technol. 1966, 39, 365-374. [CrossRef]

36. Ren, H.Y.; Sun, Z.; Zhang, L.; Wu, Y.; Huang, Q.; Wang, Y. Effect of silane coupling agents on structure and properties of silica-filled silicone rubber/styrene butadiene rubber composites. Rubber Chem. Technol. 2018, 91, 453-468. [CrossRef]

37. Kim, W.S.; Lee, D.H.; Kim, I.J.; Son, M.J.; Kim, W.; Cho, S.G. SBR/organoclay nanocomposites for the application on tire tread compounds. Macromol. Res. 2009, 17, 776-784. [CrossRef]

38. Mohanty, T.R.; Bhandari, V.; Chandra, A.K.; Chattopadhay, P.K.; Chattopadhay, S. Role of calcium stearate as a dispersion promotor for new generation carbon black-organoclay based rubber nanocomposites for tyre application. Polym. Comp. 2013, 34, 214-224. [CrossRef]

39. Lee, J.Y.; Ahn, B.; Kim, W.; Moon, H.; Paik, H.J.; Kim, W. The effect of accelerator contents on the vulcanizate structures of SSBR/silica vulcanizates. Compos. Interfaces 2017, 24, 563-577. [CrossRef]

40. Schaepertoens, M.; Didaskalou, C.; Kim, J.F.; Livingston, A.G.; Szekely, G. Solvent recycle with imperfect membranes: A semi-continuous workaround for diafiltration. J. Membr. Sci. 2016, 514, 646-658. [CrossRef]

41. Fodi, T.; Didaskalou, C.; Kupai, J.; Balogh, G.T.; Huszthy, P.; Szekely, G. Nanofiltration-Enabled In Situ Solvent and Reagent Recycle for Sustainable Continuous-Flow Synthesis. ChemSusChem 2017, 17, 3435-3444.

(C) 2018 by the authors. Licensee MDPI, Basel, Switzerland. This article is an open access article distributed under the terms and conditions of the Creative Commons Attribution (CC BY) license (http:/ / creativecommons.org/licenses/by/4.0/). 